\title{
Relation of physical activity time to incident disability in community dwelling adults with or at risk of knee arthritis: prospective cohort study
}

\author{
Dorothy D Dunlop professor ${ }^{1}$, Jing Song statistician ${ }^{1}$, Pamela A Semanik associate professor ${ }^{2}$, \\ Leena Sharma professor ${ }^{1}$, Joan M Bathon professor ${ }^{3}$, Charles B Eaton professor ${ }^{4}$, Marc C Hochberg \\ professor $^{5}$, Rebecca D Jackson professor ${ }^{6}$, C Kent Kwoh professor ${ }^{7}$, W Jerry Mysiw professor ${ }^{6}$, \\ Michael C Nevitt professor ${ }^{78}$, Rowland W Chang professor ${ }^{1}$
}

${ }^{1}$ Institute for Public Health and Medicine Center for Healthcare Studies, Feinberg School of Medicine, Northwestern University, 750 Lakeshore Drive, Chicago, IL 60611, USA; ${ }^{2}$ Rush University Medical Center, Chicago; ${ }^{3}$ Columbia University College of Physicians and Surgeons, New York, NY, USA; ${ }^{4}$ Brown University, Pawtucket, RI, USA; ${ }^{5}$ University of Maryland, Baltimore, MD, USA; ${ }^{6}$ Ohio State University, Columbus, OH, USA; ${ }^{7}$ University of Arizona College of Medicine, Tucson, AZ, USA; ${ }^{8}$ University of California at San Francisco, San Francisco, CA, USA

\begin{abstract}
Objective To investigate whether objectively measured time spent in light intensity physical activity is related to incident disability and to disability progression.

Design Prospective multisite cohort study from September 2008 to December 2012.

Setting Baltimore, Maryland; Columbus, Ohio; Pittsburgh, Pennsylvania; and Pawtucket, Rhode Island, USA.

Participants Disability onset cohort of 1680 community dwelling adults aged 49 years or older with knee osteoarthritis or risk factors for knee osteoarthritis; the disability progression cohort included 1814 adults.

Main outcome measures Physical activity was measured by accelerometer monitoring. Disability was ascertained from limitations in instrumental and basic activities of daily living at baseline and two years. The primary outcome was incident disability. The secondary outcome was progression of disability defined by a more severe level (no limitations, limitations to instrumental activities only, $1-2$ basic activities, or $\geq 3$ basic activities) at two years compared with baseline.

Results Greater time spent in light intensity activities had a significant inverse association with incident disability. Less incident disability and less disability progression were each significantly related to increasing quartile categories of daily time spent in light intensity physical activities (hazard ratios for disability onset $1.00,0.62,0.47$, and 0.58 , P for trend=0.007; hazard ratios for progression 1.00, 0.59, 0.50, and 0.53, $P$ for trend=0.003) with control for socioeconomic factors (age, sex, race/ethnicity, education, income) and health factors (comorbidities, depressive symptoms, obesity, smoking, lower extremity pain and
\end{abstract}

function, and knee assessments: osteoarthritis severity, pain, symptoms, prior injury). This finding was independent of time spent in moderate-vigorous activities.

Conclusion These prospective data showed an association between greater daily time spent in light intensity physical activities and reduced risk of onset and progression of disability in adults with osteoarthritis of the knee or risk factors for knee osteoarthritis. An increase in daily physical activity time may reduce the risk of disability, even if the intensity of that additional activity is not increased.

\section{Introduction}

Disability is a leading driver of healthcare costs, accounting for more than one in four dollars spent on healthcare. ${ }^{1}$ Medical spending among older adults is more strongly related to the presence of disability than to remaining life expectancy. ${ }^{2}$ More than $18 \%$ of people in the United States were classified as disabled in 2010, at an estimated annual cost of \$357bn ( $£ 214$ bn; €259bn). ${ }^{3}$

Participation in physical activity is a low cost, broadly applicable approach to improve health outcomes and reduce the risk of developing chronic disease. ${ }^{4-10}$ Randomized controlled trials in adults show that increased physical activity is effective in reducing disability. ${ }^{11}{ }^{12}$ Guidelines recommend 150 minutes each week of moderate to vigorous physical activity, ${ }^{13}$ but whether that intensity or time is needed to reduce disability is not known. In the absence of randomized clinical trials to evaluate a dose-response between time spent in specific 
intensities of physical activity and disability,${ }^{13}$ to inform public health interventions we examined this question by using longitudinal data from community dwelling adults at elevated risk of disability due to osteoarthritis of the knee or risk factors for knee osteoarthritis (such as obesity).

This study examined whether moderate-vigorous activity is uniquely related to a reduced risk of developing disability or whether light intensity activities may also play a role. It tested the hypothesis that more time spent in light intensity physical activity is separately related to reduced incident disability and progression of disability independent of moderate-vigorous activity and other predictors of risk of disability. We investigated the association between time spent in daily light intensity activity verifiably measured by accelerometer monitoring and subsequent two year incident disability determined from longitudinal systematic reports of limitations in instrumental and basic activities of daily living. We examined this relation among community dwelling adults at elevated risk of disability related to knee osteoarthritis or risk factors for knee osteoarthritis, whose non-sedentary time is largely characterized by light intensity activities. ${ }^{14}$

\section{Methods \\ Design overview}

This was a prospective multisite cohort study of community dwelling older adults at elevated risk of disability related to the presence of osteoarthritis of the knee or risk factors for knee osteoarthritis. Baseline measurement took place from September 2008 to December 2010; follow-up was from September 2010 to December 2012, two years after baseline assessment.

\section{Participants}

Participants were a subcohort from the Osteoarthritis Initiative (OAI). The OAI longitudinal study enrolled 4796 men and women aged 45-79 years with or at high risk of developing knee osteoarthritis, a major risk factor for disability. OAI enrollment (2004 to 2006) and biennial follow-up visits took place at four clinical sites (Baltimore, Maryland; Columbus, Ohio; Pittsburgh, Pennsylvania; and Pawtucket, Rhode Island). Adults eligible for the OAI were either required to have osteoarthritis with symptoms in at least one knee (a definite tibiofemoral osteophyte (osteophyte grade $\geq 1^{15}$ ) and pain, aching, or stiffness on most days for at least one month during the previous 12 months) or required to have at least one from a set of established risk factors for knee osteoarthritis: knee symptoms in the previous 12 months; overweight, defined using sex and age specific weight thresholds; knee injury causing difficulty walking for at least a week; history of knee surgery; family history of a total knee replacement for osteoarthritis in a biologic parent or sibling; Heberden's nodes; repetitive knee bending at work or outside work; and age 70-79 years. OAI eligibility criteria are detailed elsewhere. ${ }^{16} 17$

We drew the disability onset risk cohort free of baseline disability in instrumental or basic activities of daily living, shown in figure $1 \Downarrow$, from the 2127 participants enrolled in an OAI accelerometer monitoring substudy at the OAI 48 month clinic visit (2008-10), ${ }^{14}$ which was the baseline for the study reported here. To make statements about incident disability, we excluded 174 people reporting baseline disability limitations in instrumental or basic activities of daily living; also excluded were 179 participants with insufficient baseline accelerometer monitoring, 15 participants with incomplete outcome/covariate data, 13 decedents, and 66 participants not available two years later. After these exclusions, 1680 adults without baseline disability contributed to analyses for two year incident disability. Secondary analyses of two year disability progression evaluated a disability progression risk cohort of 1814 people free of severe baseline disability (1680 without baseline disability plus 134 with baseline mild/moderate disability, as defined below).

\section{Outcomes}

We defined disability, using the operational definition of Fried and colleagues, as "difficulty or dependency in carrying out activities essential to independent living, including essential roles, tasks needed for self-care and living independently in a home, and desired activities important to one's quality of life." 18 We identified disability from limitations in performing basic activities of daily living and higher level instrumental tasks on the basis of an affirmative response to a validated questionnaire using the stem "Exclude any difficulties you expect to last less than three months. Because of a health or memory problem do you have any difficulty. .." ${ }^{19}$ Instrumental activities of daily living tasks were preparing hot meals, grocery shopping, making telephone calls, taking drugs, and managing money. Basic activities of daily living tasks were walking across a room, dressing, bathing, eating, using the toilet, and bed transfer. When a specific task response was missing, we imputed the information from the report of extreme difficulty to a parallel item from the late life disability questionnaire for 117 (7\%) participants. ${ }^{20}$ Sensitivity assessments omitting inferred task limitations yielded almost identical results.

The primary outcome was the development of disability (instrumental or basic activities of daily living) at the two year follow-up visit among adults free of baseline disability. A secondary outcome was disability progression, based on a change from the baseline disability level to a more severe level two years later. Disability levels were none (no activities of daily living limitations), mild (only instrumental activities of daily living limitations), moderate (1-2 basic activities of daily living limitations), and severe ( $\geq 3$ basic activities of daily living limitations). ${ }^{21} 22$

\section{Primary risk factor}

Physical activity was monitored using ActiGraph GT1M accelerometers. Trained research personnel gave uniform scripted in-person instructions to wear the accelerometer for seven consecutive days on a belt at the natural waistline on the right hip in line with the right axilla from arising in the morning until retiring, except during water activities. Participants recorded on a daily log the time spent in water and cycling activities, which may not be fully captured by accelerometers.

Accelerometer output is an activity count, which is the weighted sum of the accelerations measured over a minute, where the weights are proportional to the magnitude of acceleration. We defined non-wear periods as at least 90 minutes with zero activity counts (allowing for two consecutive interrupted minutes with counts $\leq 100$ ). We identified participants with the four to seven valid monitoring days (that is, 10 or more wear hours per day) needed for reliable estimates of physical activity. ${ }^{23} \mathrm{We}$ applied intensity thresholds used by the National Cancer Institute on a minute by minute basis to identify non-sedentary activity of light intensity $(100 \leq$ counts/minute $<2020)$ and moderate to vigorous intensity (counts/minute $\geq 2020$ ) activity. ${ }^{23}$

Our primary risk factor used accelerometer assessment of physical activity measured as daily minutes spent in light or moderate-vigorous intensity activity. For analysis purposes, we determined quartile categories of time spent in light and moderate-vigorous activities by using 1680 participants without 
baseline disability. We determined quartile cut points for light activity (229, 277, and 331 average minutes/day) and moderate-vigorous activity $(4.3,12.2$, and 28.2 average minutes/day).

\section{Covariates}

Socioeconomic factors recorded were race/ethnicity (African-American, white, or other race), age, sex, education, and income. Health factors were comorbid chronic conditions, knee specific health factors, and health behaviors. In addition to osteoarthritis, chronic conditions ascertained by self report of diagnosis by a physician were cancer, cerebrovascular disease, congestive heart failure, diabetes, gastrointestinal disease, pulmonary disease, kidney problems, myocardial infarction, other rheumatic disease, and vascular disease. Body mass index was classified as normal (18.5-24.9), overweight (25.0-29.9), or obese (30 and above) calculated from measured height and weight (weight $(\mathrm{kg}) /$ height $(\mathrm{m})^{2}$ ). Severity of depressive symptoms was ascertained by the Center for Epidemiological Studies depression scale (range 0-60). ${ }^{24}$ Self reported lower extremity symptoms were pain, aching, or stiffness in the ankle or foot for more than half the previous 30 days or in the hip in the previous 12 months. Knee specific health factors were person level severity of knee osteoarthritis (highest Kellgren-Lawrence grade of both knees assessed from a "fixed flexion" knee radiography protocol at or before the OAI 48 month assessment $)^{25}$; knee symptoms defined as pain, aching, or stiffness on most days of a month during the previous year in either knee; self reported previous knee injury resulting in walking difficulty for at least one week; and person level severity of knee pain (highest (worst) Western Ontario and McMaster University Osteoarthritis pain index score of both knees; range 0-20). If a baseline (OAI 48 month visit) health factor was missing $(2.6 \%, \mathrm{n}=47)$, we used the most recent annual assessment as a proxy. Health behaviors included the report of current smoking and function ascertained by gait speed based on a 20 foot walk test.

\section{Statistical analyses}

Univariate analyses of linear trend effects used a

Mantel-Haenszel test for ordinal categories, $\chi^{2}$ test for nominal categories, and linear regression for continuous characteristics. We estimated hazard ratios from survival analysis for discrete data in 1680 adults free of baseline disability to investigate a graded relation between baseline physical activity quartile categories and the development of disability within two years. ${ }^{26}$ Secondary analyses evaluated hazard ratios for disability progression among 1814 adults free of severe disability at baseline. Recognizing that systematic differences between people included in and excluded from the analysis sample could influence our findings, we did weighted analyses as recommended by Hogan. ${ }^{27}$ For simplicity, we report unweighted analyses, because weighted analyses mirrored those findings. Sensitivity analyses evaluated the stability of results to the cut point separating moderate-vigorous from light intensity activity suggested by Triano and colleagues (that is, 2020 counts/minute ${ }^{23}$ ) by using alternative cut points in the accelerometer literature $\left(1952^{28}\right.$ and $\left.1269^{29}\right)$. These analyses regressed the hazard for disability onset on quartile categories of light activity time based on alternative cut points, controlling for socioeconomic and health factors and moderate-vigorous physical activity. Our analyses used public data from the Osteoarthritis Initiative (www.oai.ucsf.edu/datarelease/). Statistical testing used a nominal $\alpha=0.05$ level, and we used SAS software version 9.3.

\section{Results}

We documented 149 cases of new disability in instrumental or basic activities of daily living over two years among the 1680 adults aged 49-83 years and free of baseline disability with or at high risk of osteoarthritis of the knee who completed accelerometer physical activity monitoring, disability assessments, and covariate data. This cohort averaged 302 minutes/day of non-sedentary activity, of which the vast majority was light intensity activities (284 minutes/day). Table $1 \Downarrow$ shows the baseline characteristics of this cohort stratified by quartile categories of light activity time. Participants who spent the least time in light physical activities were more likely to be older, male, and obese and to have comorbidities, severe knee osteoarthritis, and poorer function and less likely to have lower extremity symptoms.

\section{Primary outcome: incident disability}

Light activity time at baseline had a strong inverse relation with the development of disability. In age adjusted analyses shown in figure $2 \Downarrow$, the frequency of incident disability two years later was greatest among the quartile categories who spent the least time in light physical activity and the least time in moderate-vigorous activity. Stratified age adjusted analyses (not shown) showed significantly lower frequencies of incident disability related to greater light activity time among men $(\mathrm{n}=765$; hazard ratios $1.00,0.51,0.48$, and 0.56 ; $\mathrm{P}$ for trend=0.042), women ( $\mathrm{n}=915$; hazard ratios $1.00,0.64,0.42$, and 0.56 ; $\mathrm{P}$ for trend=0.037), adults with knee osteoarthritis $(\mathrm{n}=1006$; hazard ratios $1.00,0.67,0.43$, and 0.64 ; $\mathrm{P}$ for trend $=0.037$ ), and adults without knee osteoarthritis $(\mathrm{n}=674$; hazard ratios 1.00, 0.43, 0.47, and 0.46; $\mathrm{P}$ for trend $=0.042$ ). We found similar significant trends in relation to quartile categories of daily moderate-vigorous activity time stratified by men $(\mathrm{n}=765$; hazard ratios $1.00,0.58,0.42$, and 0.29 ; $\mathrm{P}$ for trend $<0.001)$, women $(\mathrm{n}=915$; hazard ratios $1.00,0.38,0.53$, and 0.20; $\mathrm{P}$ for trend $<0.001$ ), adults with knee osteoarthritis $(\mathrm{n}=1006$; hazard ratio $1.00,0.65,0.47$, and 0.35 ; $\mathrm{P}$ for trend $<0.001)$, and adults without knee osteoarthritis $(n=674$; hazard ratios 1.00, 0.25, 0.49, and 0.18; $\mathrm{P}$ for trend=0.001).

In multivariate analyses (table $2 \Downarrow$ ), greater time spent in light activities was significantly related to lower risk of developing disability in instrumental or basic activities of daily living after simultaneous control for socioeconomic and health factors. For increasing quartile categories of light activity time, the hazard ratios for incident disability decreased: $1.00,0.62,0.47$, and 0.58 , respectively ( $\mathrm{P}$ for trend $=0.007$ ). A significant relation persisted after further control for time spent in moderate-vigorous activities (hazard ratios 1.00, 0.64, 0.51, and 0.67 ; $\mathrm{P}$ for trend $=0.039$ ). The only other significant multivariate predictors of incident disability (not shown) were depression and lower extremity pain (see supplementary tables).

We found a strong association between increasing quartile categories of moderate-vigorous activity time and reduced risk of incident disability in multivariate analyses controlled for socioeconomics, health factors, and time in light activities (hazard ratios 1.00, 0.57, 0.63, and 0.38; $\mathrm{P}$ for trend $=0.005$ ) (table $2 \Downarrow$ ). These findings show a decreased risk of subsequent incident disability associated with greater daily time spent in light activities and in moderate-vigorous activities. Furthermore, the inverse relation of light intensity activity time with disability was independent of moderate-vigorous activity time and vice versa. 


\section{Secondary outcome: disability progression}

Recognizing that many older adults in the community live with disabilities, we broadened our analyses to evaluate progression of disability among 1814 adults free of severe baseline limitations in instrumental or basic activities of daily living. In age adjusted analyses shown in figure $3 \Downarrow$, the greatest disability progression occurred among quartile categories who spent the least time in light physical activity and the least time in moderate-vigorous activity. This inverse graded relation persisted in multivariate analyses controlled for socioeconomic factors, health factors, and moderate-vigorous activity time (table $3 \Downarrow$ ). The hazard ratios for disability progression decreased across increasing quartile categories of light activity time (1.00, $0.61,0.54$, and 0.60; $P$ for trend=0.018). Similarly, we found a significant inverse graded relation between quartile categories representing more time spent in moderate-vigorous activities and disability progression, with control for socioeconomic factors, health factors, and light activity time (hazard ratios 1.00, $0.68,0.66$, and 0.41 ; $\mathrm{P}$ for trend=0.007).

\section{Sensitivity analyses}

We did sensitivity analyses (not shown) in which we added 79 decedents/withdrawals by attributing to each the worst disability outcome. Results showed a significant inverse relation of light activity time quartile categories with incident disability and with disability progression, with control for socioeconomic factors, health factors, and moderate-vigorous activity time. Similarly, we found a significant inverse relation of moderate-vigorous activity time quartile categories with incident disability and with disability progression, with control for socioeconomic factors, health factors, and light activity time. Finally, sensitivity analyses based on alternative cut points defining light physical activity showed an inverse association with the development of disability, with control for socioeconomic factors, health factors, and moderate-vigorous activity time (cut point=1952 counts/minute: significant trend; cut point=1269: trend present but attenuated to non-significant).

\section{Discussion}

The primary finding from this longitudinal study in community dwelling adults with or at high risk of osteoarthritis of the knee shows a significant inverse relation between daily time spent in light intensity physical activity and risk of developing disability. Importantly, this relation was independent of the time spent in moderate or vigorous activities. This finding is important because adults who are not candidates to increase the intensity of activity owing to health limitations may benefit from increasing the time spent in light intensity activities. As expected, we found an inverse relation between daily time spent in moderate-vigorous activities and the development of disability, consistent with the many health benefits tied to physical activity of moderate or vigorous intensity. ${ }^{30-35}$ Together, these findings suggest that increasing daily time spent being physically active may reduce the risk of disability, irrespective of the intensity of that additional activity.

Notably, all quartile categories representing greater daily time in light activities showed a significantly reduced risk of incident disability compared with the group with the least daily light activity time. An average person in the second quartile category of light activity (mean 255 minutes/day) had a $43 \%$ reduction in the age adjusted hazard for developing disability compared with the average person in the quartile category spending the least time in light activity (mean 192 minutes/day). Small increases in moderate-vigorous activity were associated with a reduced risk of disability. An average person in the second quartile category of moderate-vigorous activity time (mean 18 minutes/day) had a 53\% reduction in the age adjusted hazard for developing disability compared with the average person in the quartile category spending the least time in moderate-vigorous activity (mean 12 minutes/day). The reduction in risk of incident disability related to small time increments in moderate-vigorous activity bolsters the recognized benefits of those activities. Our findings additionally suggest that increasing time spent in physical activity through light activities may be beneficial towards the goal of maintaining personal independence.

A striking inverse relation between time spent in light activity and incident disability was seen in the group of adults with knee osteoarthritis. This finding is relevant to more than 250 million people worldwide with knee osteoarthritis. ${ }^{36}$ Nearly two thirds of obese adults are expected to develop symptoms of knee osteoarthritis at some point in their lives. ${ }^{37}$ Osteoarthritis affecting the knee is a primary cause of arthritis related disability and its costs. ${ }^{38}{ }^{39}$ A major cost component related to knee osteoarthritis is total knee replacement surgery. The demand for total knee arthroplasties is expected to more than double in the next decade. ${ }^{40}$ As many as half of adults with osteoarthritis of the knee are inactive, ${ }^{14}{ }^{41}$ on the basis of US federal guidelines (that is, absence of any moderate activity lasting at least 10 minutes over an entire week $^{13}$ ). Such inactive people could substantially reduce their risk of disability and potentially postpone or eliminate the need for arthroplasty in end stage disease by increasing the time spent in physical activity of any intensity.

\section{Findings in relation to other studies}

Although the beneficial effects of participation in regular physical activity are widely accepted, the potential benefit of light intensity activity is unclear. Randomized controlled trials focus on benefits of moderate and vigorous physical activity. Exercise programs are effective in reducing mortality and can improve disease related symptoms such as pain, functional limitation, and depression. ${ }^{49104243}$ Randomized control trials show a dose-response relation of greater intensity or intensity/frequency of exercise with improved cardiovascular fitness, fewer functional limitations, and less depression. ${ }^{4} 12445$ An important randomized control trial by Martin and colleagues showed a dose-response relation between a program delivering four levels of exercise intensity/frequency and reduced disability scores over six months. ${ }^{46}$ Published prospective observational studies such as those summarized by Paterson and colleagues show an inverse relation between increasing self reported activity intensity levels (for example, sedentary, light intensity, moderate intensity) or escalating intensity/frequency levels and the development of disability. ${ }^{47}$

In contrast to these studies, we evaluated the relation of time spent in verifiable light intensity activities with subsequent disability. Our study using objective physical activity measures shows a reduced risk of developing disability related to greater time spent in light intensity physical activities. Importantly, this relation held after we controlled for time spent in moderate-vigorous activity and other predictors of risk of disability. To our knowledge, this study is the first to show an inverse relation between light activity time and the development of disability.

Moderate-vigorous activity is well established as being related to good health outcomes, including reduced disability. Our results indicate that increasing light activity is also beneficial, 
independent of moderate-vigorous activity. Our findings support the testing of interventions to increase both light and moderate-vigorous activity. Our results have implications for adults who may not be candidates for participating in moderate activity, such as people who are limited by cardiac or pulmonary restrictions or have mobility barriers due to pain. These results indicate that increasing light activity independent of moderate-vigorous activity may be related to less subsequent disability.

\section{Strengths and weaknesses of study}

Strengths of this study included prospective data collection across multiple sites, the large sample size, and the age and sex diversity of this sample. Results from this observational study may be influenced by reverse causation or confounded by factors associated with unmeasured disability at baseline, influencing both low levels of physical activity and increased risk of disability. We mitigated this concern by restricting our analyses to people free of disability at baseline, assessing subsequent disability status two years later, and controlling for baseline gait speed, which is arguably a precursor of disability. In addition, our analyses controlled for major confounders including baseline chronic conditions, socioeconomic factors, obesity status, depressive symptoms, and pain to minimize this concern. Although multivariate control for potential confounders attenuated the beneficial relation of light activity time to incident disability, the only significant factors were depressive symptoms and lower extremity pain, showing the strength of physical activity relative to these other recognized but non-significant risk factors.

The sample was composed of adults with or at high risk of developing knee osteoarthritis, which influences the generalizability of these results. However, the relation between time spent in light activity and incident disability held within subgroups with and without knee osteoarthritis, supporting the robustness of this relation to disease status. Although an important methodological strength is the objective measurement of physical activity with accelerometers, the cut point used to define light intensity activity may influence the strength of association with disability. Finally, causation cannot be inferred from these observational data.

\section{Conclusions}

These prospective data from a large study of diverse community dwelling adults with or at high risk of knee osteoarthritis showed a significant and consistent relation between greater time spent in light intensity activity and a reduced risk of development or progression of disability. Our findings confirm that more moderate-vigorous activity time was related to less subsequent onset and progression of disability. Importantly, greater light activity time, independent of time spent in moderate-vigorous intensity activity, was significantly related to reduced risk and progression of disability. Our findings provide encouragement for adults who may not be candidates to increase the intensity of physical activity owing to health limitations. Greater daily physical activity time may reduce the risk of disability, even if the intensity of that additional activity is not increased.

We gratefully acknowledge expertise from Jennifer Hootman of the US Department of Health and Human Services Physical Activity Guidelines Advisory Committee.

Contributors: DDD designed the study, analyzed and interpreted the data, and wrote the manuscript. RWC and PAS contributed to the study design, interpretation of the data, and writing of the manuscript. JS provided statistical advice, analyzed and interpreted the data, and commented on drafts of the manuscript. MCN and CKK provided methodological advice and made significant contributions to drafts of the manuscript. LS, JMB, CBE, MCH, RDJ, and WJM provided clinical advice and commented on drafts of the manuscript. All authors accept full responsibility for the conduct of the study, had access to the data, and controlled the decision to publish. DDD is the guarantor.

Funding: This study is funded in part by National Institute for Arthritis and Musculoskeletal Diseases (grant No R01- AR054155,

R21-AR059412, and P60-AR064464) and by the Falk Medical Trust. The publicly released Osteoarthritis Initiative (OAI) data were funded through a public-private partnership comprising five contracts (N01-AR-2-2258, N01-AR-2-2259, N01-AR-2-2260, N01-AR-2-2261, N01-AR-2-2262) awarded by the National Institutes of Health, a branch of the Department of Health and Human Services. Private funding partners include Merck Research Laboratories, Novartis Pharmaceuticals Corporation, GlaxoSmithKline, and Pfizer. Private sector funding for the OAl is managed by the Foundation for the National Institutes of Health. The funders had no role in the collection, management, analysis, and interpretation of the data; the writing of the manuscript; or the decision to submit the manuscript for publication. The content of this report is solely the responsibility of the authors and does not necessarily represent the official views of the National Institutes of Health, the private funding partners, or the Osteoarthritis Initiative.

Competing interests: All authors have completed the ICMJE uniform disclosure form at www.icmje.org/coi_disclosure.pdf and declare: support for the submitted work as detailed above; no financial relationships with any organizations that might have an interest in the submitted work in the previous three years; no other relationships or activities that could appear to have influenced the submitted work.

Ethical approval: This study was approved by the Institutional Review Board of Northwestern University, Chicago, IL. Institutional review board approval was obtained at participating sites.

Data sharing: This study used public data from the Osteoarthritis Initiative, which is available at http://oai.epi-ucsf.org/datarelease/ DataClinical.asp.

Transparency: The lead author (the manuscript's guarantor) affirms that the manuscript is an honest, accurate, and transparent account of the study being reported; that no important aspects of the study have been omitted; and that any discrepancies from the study as planned have been explained.

Anderson WL, Armour BS, Finkelstein EA, Wiener JM. Estimates of state-level health-care expenditures associated with disability. Public Health Rep 2010:125:44-51.

2 Lubitz J, Cai L, Kramarow E, Lentzner $\mathrm{H}$. Health, life expectancy, and health care spending among the elderly. N Engl J Med 2003;349:1048-55.

3 Brault MW. Americans with disabilities: 2010. US Bureau of the Census, US Department of Commerce, 2012:1-23.

4 Church TS, Earnest CP, Skinner JS, Blair SN. Effects of different doses of physical activity on cardiorespiratory fitness among sedentary, overweight or obese postmenopausal women with elevated blood pressure: a randomized controlled trial. JAMA 2007:297:2081-91.

5 Willis BL, Gao A, Leonard D, Defina LF, Berry JD. Midlife fitness and the development of chronic conditions in later life. Arch Intern Med 2012;172:1333-40.

6 Larson EB, Wang L, Bowen JD, McCormick WC, Teri L, Crane P, et al. Exercise is associated with reduced risk for incident dementia among persons 65 years of age and older. Ann Intern Med 2006;144:73-81.

7 Gill TM, Gahbauer EA, Murphy TE, Han L, Allore HG. Risk factors and precipitants of long-term disability in community mobility: a cohort study of older persons. Ann Intern Med 2012;156:131-40.

8 Lin JS, O'Connor E, Whitlock EP, Beil TL. Behavioral counseling to promote physical activity and a healthful diet to prevent cardiovascular disease in adults: a systematic review for the U.S. Preventive Services Task Force. Ann Intern Med 2010;153:736-50.

9 Fong DY, Ho JW, Hui BP, Lee AM, Macfarlane DJ, Leung SS, et al. Physical activity for cancer survivors: meta-analysis of randomised controlled trials. BMJ 2012;344:e70.

10 Chalder M, Wiles NJ, Campbell J, Hollinghurst SP, Haase AM, Taylor AH, et al. Facilitated physical activity as a treatment for depressed adults: randomised controlled trial. $B M J$ 2012;344:e2758

11 Penninx BW, Messier SP, Rejeski WJ, Williamson JD, DiBari M, Cavazzini C, et al. Physical exercise and the prevention of disability in activities of daily living in older persons with osteoarthritis. Arch Intern Med 2001;161:2309-16.

12 Martin CK, Church TS, Thompson AM, Earnest CP, Blair SN. Exercise dose and quality of life: a randomized controlled trial. Arch Intern Med 2009;169:269-78.

13 Physical Activity Guidelines Advisory Committee. Physical Activity Guidelines Advisory Committee report. US Department of Health and Human Services, 2008. 


\section{What is already known on this topic}

Disability is a leading driver of healthcare costs, accounting for more than one in four dollars spent on healthcare

Participation in physical activity is a low cost, broadly applicable approach to improve health outcomes including reduction of disability Physical activity guidelines recommend engaging in moderate-vigorous intensity physical activity, but whether that intensity is needed to reduce disability is not known

\section{What this study adds}

Greater daily time spent in light intensity physical activities objectively measured by accelerometer was significantly related to a reduced risk of developing disability and disability progression

Importantly, this relation held after control for daily time spent in moderate-vigorous intensity activities and other predictors of disability risk

These findings suggest that more time spent being physically active reduces the risk of disability even if the intensity of activity is not increased

14 Dunlop DD, Song J, Semanik PA, Chang RW, Sharma L, Bathon JM, et al. Objective physical activity measurement in the osteoarthritis initiative: are guidelines being met? Arthritis Rheum 2011;63:3372-82.

15 Altman RD, Hochberg M, Murphy WA Jr, Wolfe F, Lequesne M. Atlas of individual radiographic features in osteoarthritis. Osteoarthritis Cartilage 1995;3(suppl A):3-70.

16 Eckstein F, Wirth W, Nevitt MC. Recent advances in osteoarthritis imaging-the osteoarthritis initiative. Nat Rev Rheumatol 2012;8:622-30.

17 Osteoarthritis Initiative. Data news. 2013. www.oai.ucsf.edu/datarelease/.

18 Fried LP, Ferrucci L, Darer J, Williamson JD, Anderson G. Untangling the concepts of disability, frailty, and comorbidity: implications for improved targeting and care. J Geronto A Biol Sci Med Sci 2004;59:255-63.

19 Rodgers W, Miller B. A comparative analysis of ADL questions in surveys of older people. $J$ Gerontol B Psychol Sci Soc Sci 1997:52:21-36.

20 Jette AM, Haley SM, Coster WJ, Kooyoomjian JT, Levenson S, Heeren T, et al. Late life function and disability instrument: I. Development and evaluation of the disability component. J Gerontol A Biol Sci Med Sci 2002;57:M209-16.

21 Miller ME, Rejeski WJ, Reboussin BA, Ten Have TR, Ettinger WH. Physical activity, functional limitations, and disability in older adults. J Am Geriatr Soc 2000;48:1264-72.

22 Yang Y, George LK. Functional disability, disability transitions, and depressive symptoms in late life. J Aging Health 2005;17:263-92.

23 Troiano RP, Berrigan D, Dodd KW, Masse LC, Tilert T, McDowell M. Physical activity in the United States measured by accelerometer. Med Sci Sports Exerc 2008;40:181-8.

24 Pandya R, Metz L, Patten SB. Predictive value of the CES-D in detecting depression among candidates for disease-modifying multiple sclerosis treatment. Psychosomatics 2005:46:131-4.

25 Peterfy C, Li J, Zaim S, Duryea J, Lynch J, Miaux Y, et al. Comparison of fixed-flexion positioning with fluoroscopic semi-flexed positioning for quantifying radiographic joint-space width in the knee: test-retest reproducibility. Skeletal Radiol 2003;32:128-32.

26 Prentice R, Gloeckler L. Regression analysis of group survival data with applications to breast cancer. Biometrics 1978;347:57-67.

27 Hogan JW, Roy J, Korkontzelou C. Handling drop-out in longitudinal studies. Stat Med 2004;23:1455-97.

28 Freedson PS, Melanson E, Sirard J. Calibration of the Computer Science and Applications, Inc. accelerometer. Med Sci Sports Exerc 1998;30:777-81.

29 Loprinzi PD, Lee H, Cardinal BJ, Crespo CJ, Andersen RE, Smit E. The relationship of actigraph accelerometer cut-points for estimating physical activity with selected health outcomes: results from NHANES 2003-06. Res Q Exerc Sport 2012;83:422-30.

30 Weuve J, Kang JH, Manson JE, Breteler MM, Ware JH, Grodstein F. Physical activity, including walking, and cognitive function in older women. JAMA 2004;292:1454-61.

31 Blair SN, Church TS. The fitness, obesity, and health equation: is physical activity the common denominator? JAMA 2004;292:1232-4.

32 Rejeski WJ, Ip EH, Bertoni AG, Bray GA, Evans G, Gregg EW, et al. Lifestyle change and mobility in obese adults with type 2 diabetes. N Engl J Med 2012;366:1209-17.

33 Manini TM, Everhart JE, Patel KV, Schoeller DA, Colbert LH, Visser M, et al. Daily activity energy expenditure and mortality among older adults. JAMA 2006;296:171-9.

34 Lee IM, Rexrode KM, Cook NR, Manson JE, Buring JE. Physical activity and coronary heart disease in women: is "no pain, no gain" passé? JAMA 2001;285:1447-54.
35 Bates JH, Serdula MK, Khan LK, Jones DA, Macera CA, Ainsworth BE Intensity of physica activity and risk of coronary heart disease. JAMA 2001;285:2973; author reply 2974.

36 Dillon CF, Rasch EK, Gu Q, Hirsch R. Prevalence of knee osteoarthritis in the United States: arthritis data from the Third National Health and Nutrition Examination Survey 1991-94. J Rheumatol 2006;33:2271-9.

37 Murphy L, Schwartz TA, Helmick CG, Renner JB, Tudor G, Koch G, et al. Lifetime risk of symptomatic knee osteoarthritis. Arthritis Rheum 2008:59:1207-13.

38 Lawrence RC, Felson DT, Helmick CG, Arnold LM, Choi H, Deyo RA, et al. Estimates of the prevalence of arthritis and other rheumatic conditions in the United States: part II. Arthritis Rheum 2008;58:26-35.

39 Cram P, Lu X, Kates SL, Singh JA, Li Y, Wolf BR. Total knee arthroplasty volume, utilization, and outcomes among Medicare beneficiaries, 1991-2010. JAMA 2012;308:1227-36.

40 Kurtz S, Ong K, Lau E, Mowat F, Halpern M. Projections of primary and revision hip and knee arthroplasty in the United States from 2005 to 2030. J Bone Joint Surg Am 2007;89:780-5.

41 Voelker R. Few adults with knee osteoarthritis meet national guidelines for physical activity. JAMA 2011;306:1428-30.

42 Messier SP, Mihalko SL, Legault C, Miller GD, Nicklas BJ, DeVita P, et al. Effects of intensive diet and exercise on knee joint loads, inflammation, and clinical outcomes among overweight and obese adults with knee osteoarthritis: the IDEA randomized clinical trial. JAMA 2013;310:1263-73.

43 Ettinger WH Jr, Burns R, Messier SP, Applegate W, Rejeski WJ, Morgan T, et al. A randomized trial comparing aerobic exercise and resistance exercise with a health education program in older adults with knee osteoarthritis: the Fitness Arthritis and Seniors education program in older adults with

44 Dunn AL, Trivedi MH, Kampert JB, Clark CG, Chambliss HO. Exercise treatment for depression: efficacy and dose response. Am J Prev Med 2005;28:1-8.

45 Lee IM, Skerrett PJ. Physical activity and all-cause mortality: what is the dose-response relation? Med Sci Sports Exerc 2001;33:S459-71; discussion S493-54.

46 Lane NE. Osteoarthritis of the hip. N Engl J Med 2007;357:1413-21.

47 Paterson DH, Warburton DE. Physical activity and functional limitations in older adults: a systematic review related to Canada's physical activity guidelines. Int J Behav Nutr Phys Act 2010;7:38

\section{Accepted: 23 March 2014}

\section{Cite this as: BMJ 2014;348:92472}

This is an Open Access article distributed in accordance with the Creative Commons Attribution Non Commercial (CC BY-NC 3.0) license, which permits others to distribute, remix, adapt, build upon this work non-commercially, and license their derivative works on different terms, provided the original work is properly cited and the use is non-commercial. See: http://creativecommons.org/licenses/by-nc/3.0/. 


\section{Tables}

\begin{tabular}{|c|c|c|c|c|c|}
\hline \multirow[b]{2}{*}{ Characteristics } & \multicolumn{4}{|c|}{ Quartile category of light physical activity daily time } & \multirow{2}{*}{$\begin{array}{l}\text { P value } \\
\text { (trend) }^{*}\end{array}$} \\
\hline & 1 (lowest) $(n=423)$ & $2(n=415)$ & $3(n=423)$ & 4 (highest) (n=419) & \\
\hline \multicolumn{6}{|l|}{ Socioeconomic factors } \\
\hline Mean (SD) age in years & $67.8(9.7)$ & $65.3(8.9)$ & $63.9(8.5)$ & $62.4(7.9)$ & $<0.001$ \\
\hline White race/ethnicity & $85.8(363)$ & $87.0(361)$ & $84.9(359)$ & $81.4(341)$ & 0.370 \\
\hline Female sex & $43.3(183)$ & $51.1(212)$ & $59.6(252)$ & $64.0(268)$ & $<0.001$ \\
\hline Education: high school or less & $11.1(47)$ & $12.8(53)$ & $11.4(48)$ & $13.4(56)$ & 0.453 \\
\hline Income $<\$ 50000 \dagger$ & $33.1(140)$ & $28.2(117)$ & $28.6(121)$ & $32.9(138)$ & 0.986 \\
\hline \multicolumn{6}{|l|}{ Health factors } \\
\hline \multicolumn{6}{|l|}{ Body mass index: } \\
\hline Normal: $20-25$ & $22.7(96)$ & $26.5(110)$ & $26.7(113)$ & $28.4(119)$ & 0.006 \\
\hline Overweight: 25-29.9 & 35.9 (152) & $41.0(170)$ & $40.9(173)$ & $39.9(167)$ & \\
\hline Obese: $\geq 30$ & $41.4(175)$ & $32.5(135)$ & $32.4(137)$ & $31.7(133)$ & \\
\hline \multicolumn{6}{|l|}{ Comorbidity } \\
\hline Cancer & $8.0(34)$ & $5.5(23)$ & $2.8(12)$ & $4.1(17)$ & 0.002 \\
\hline Cerebrovascular disease & $5.4(23)$ & $3.9(16)$ & $1.7(7)$ & $2.4(10)$ & 0.004 \\
\hline Congestive heart failure & $4.5(19)$ & $1.7(7)$ & $1.9(8)$ & $1.4(6)$ & 0.007 \\
\hline Diabetes & $13.5(57)$ & $6.5(27)$ & $10.6(45)$ & $8.4(35)$ & 0.081 \\
\hline Gastrointestinal disease & $2.6(11)$ & $2.7(11)$ & $2.1(9)$ & $1.4(6)$ & 0.209 \\
\hline Pulmonary disease & $11.8(50)$ & $8.9(37)$ & $6.9(29)$ & $12.2(51)$ & 0.867 \\
\hline Kidney problems & $2.6(11)$ & $2.2(9)$ & $1.7(7)$ & $1.0(4)$ & 0.063 \\
\hline Myocardial infarction & $2.8(12)$ & $1.7(7)$ & $2.6(11)$ & $1.9(8)$ & 0.562 \\
\hline $\begin{array}{l}\text { Rheumatic disease other than } \\
\text { osteoarthritis }\end{array}$ & $3.8(16)$ & $1.0(4)$ & $1.7(7)$ & $1.9(8)$ & 0.111 \\
\hline Vascular disease & $1.9(8)$ & $1.5(6)$ & $0.5(2)$ & $1.2(5)$ & 0.204 \\
\hline $\begin{array}{l}\text { Mean (SD) depressive } \\
\text { symptom score§ }\end{array}$ & $6.8(7.5)$ & $6.0(6.8)$ & $5.8(7.0)$ & $6.6(7.1)$ & 0.598 \\
\hline $\begin{array}{l}\text { Lower extremity pain, aching, } \\
\text { or stiffness } \uparrow\end{array}$ & $51.8(219)$ & $59.0(245)$ & $58.9(249)$ & $63.5(266)$ & 0.001 \\
\hline \multicolumn{6}{|l|}{ Knee osteoarthritis severity*: } \\
\hline Grade 0 or 1 & $37.1(157)$ & $40.7(169)$ & $40.4(171)$ & $42.2(177)$ & \multirow[t]{4}{*}{0.045} \\
\hline Grade 2 & $30.5(129)$ & $31.1(129)$ & $31.0(131)$ & $30.6(128)$ & \\
\hline Grade 3 & $21.3(90)$ & $20.0(83)$ & $19.6(83)$ & $20.5(86)$ & \\
\hline Grade 4 & $11.1(47)$ & $8.2(34)$ & $9.0(38)$ & $6.7(28)$ & \\
\hline Knee symptoms†† & $37.4(158)$ & $37.6(156)$ & $39.7(168)$ & $36.3(152)$ & 0.920 \\
\hline Previous knee injury & $51.5(218)$ & $49.2(204)$ & $48.7(206)$ & $51.3(215)$ & 0.913 \\
\hline Mean (SD) knee pain $\neq \ddagger$ & $2.7(3.2)$ & $2.3(2.9)$ & $2.3(2.9)$ & $2.6(3.2)$ & 0.676 \\
\hline Current smoker & $4.0(17)$ & $3.4(14)$ & $2.4(10)$ & $4.3(18)$ & 0.959 \\
\hline $\begin{array}{l}\text { Function: mean (SD) gait } \\
\text { speed in feet/second }\end{array}$ & $4.3(0.7)$ & $4.4(0.6)$ & $4.5(0.6)$ & $4.5(0.6)$ & $<0.001$ \\
\hline \multicolumn{6}{|l|}{ Physical activity } \\
\hline $\begin{array}{l}\text { Mean (SD) light activity in } \\
\text { minutes/day }\end{array}$ & $192.3(29.2)$ & $254.9(14.2)$ & $302.1(15.7)$ & $385.9(50.0)$ & $<0.001$ \\
\hline $\begin{array}{l}\text { Mean (SD) moderate-vigorous } \\
\text { activity in minutes/day }\end{array}$ & $13.1(17.6)$ & $18.0(19.2)$ & $20.3(18.6)$ & $24.3(20.9)$ & $<0.001$ \\
\hline
\end{tabular}

${ }^{*}$ Test for trend used Mantel-Haenszel $\mathrm{x}^{2}$ test $(\mathrm{df}=1)$ except for $\mathrm{x}^{2}$ test for overall differences for race and sex comparisons, and linear regression for continuous factors age, depressive symptom score, knee pain, gait speed, light activity minutes/day, and moderate activity minutes/day. flncome less than $\$ 50000$ ( $\$ 30000 ; € 36000$ ) per year or not reported. 


\section{Table 1 (continued)}

\begin{tabular}{|c|c|c|c|c|c|}
\hline \multirow[b]{2}{*}{ Characteris } & \multicolumn{4}{|c|}{ Quartile category of light physical activity daily time } & \\
\hline & 1 (lowest) $(n=423)$ & $2(n=415)$ & $3(n=423)$ & 4 (highest) (n=419) & $(\text { trend })^{\star}$ \\
\hline
\end{tabular}

$\ddagger$ Participants could contribute to more than one of listed comorbidities.

$\S$ Center for Epidemiological Studies depression score.

\Hip, ankle, or foot.

${ }^{* *}$ Highest Kellgren-Lawrence grade of both knees.

††Knee symptoms based on report of pain, aching, or stiffness most days in month for previous 12 months.

$\ddagger \ddagger$ Western Ontario and McMaster University osteoarthritis index pain score. 
Table 2| Hazard ratios for onset of disability $(n=1680)$ among quartile categories light activity time and moderate-vigorous activity time

\begin{tabular}{|c|c|c|c|c|c|}
\hline & \multicolumn{4}{|c|}{ Quartile categories-hazard ratio $(95 \% \mathrm{Cl})$ relative to category 1} & \multirow[b]{2}{*}{$P$ value (trend) $\dagger$} \\
\hline & 1 (least time) & 2 & 3 & 4 (most time) & \\
\hline \multicolumn{6}{|c|}{ Categories defined from daily light intensity activity timeł } \\
\hline Unadjusted & 1.00 & 0.56 (0.37 to 0.86$)$ & 0.43 (0.27 to 0.68$)$ & $0.54(0.35$ to 0.83$)$ & 0.001 \\
\hline $\begin{array}{l}\text { Socioeconomic§ and health } \mathbb{} \\
\text { factors }\end{array}$ & 1.00 & $0.62(0.40$ to 0.96$)$ & $0.47(0.29$ to 0.76$)$ & $0.58(0.36$ to 0.92$)$ & 0.007 \\
\hline $\begin{array}{l}\text { Socioeconomic§ and health } \uparrow \\
\text { factors plus } \\
\text { moderate-vigorous activity }\end{array}$ & 1.00 & 0.64 (0.41 to 0.99$)$ & 0.51 (0.31 to 0.83$)$ & $0.67(0.41$ to 1.07$)$ & 0.039 \\
\hline \multicolumn{6}{|c|}{ Categories defined from daily moderate-vigorous activity time ${ }^{\star \star}$} \\
\hline Unadjusted & 1.00 & 0.49 (0.32 to 0.74$)$ & 0.51 (0.34 to 0.78$)$ & $0.28(0.17$ to 0.47$)$ & $<0.001$ \\
\hline $\begin{array}{l}\text { Socioeconomic§ and health } \uparrow \\
\text { factors }\end{array}$ & 1.00 & 0.54 (0.34 to 0.85$)$ & 0.57 (0.35 to 0.92$)$ & $0.34(0.18$ to 0.62$)$ & $<0.001$ \\
\hline $\begin{array}{l}\text { Socioeconomic§ and health } \boldsymbol{T} \\
\text { factors plus light activity }\end{array}$ & 1.00 & 0.57 (0.36 to 0.91$)$ & 0.63 (0.38 to 1.04$)$ & 0.38 (0.20 to 0.72$)$ & 0.005 \\
\hline
\end{tabular}

*Ascertained from instrumental or basic activities of daily living task limitations.

†Linear trend test.

łLight activity quartile categories in minutes per day: Q1, <229 ( $n=423) ;$ Q2, 229-275 ( $n=415) ;$ Q3, 275-328 ( $n=423) ;$ Q4, $\geq 328(n=419)$.

§Age, sex, race/ethnicity, education, and income.

TComorbidities (cancer, cerebrovascular disease, congestive heart failure, diabetes, gastrointestinal disease, pulmonary disease, kidney problems, myocardial

infarction, rheumatic disease other than osteoarthritis, vascular disease), Center for Epidemiological Studies depression score, body mass index category, current smoking, knee osteoarthritis severity (Kellgren-Lawrence grade), knee pain (Western Ontario and McMaster University osteoarthritis score), knee symptoms, knee injury, other lower extremity joint pain, gait speed.

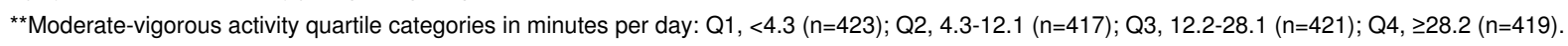


Table 3| Hazard ratio for disability progression* $(\mathrm{n}=1814)$ among quartile categories of light activity time and moderate-vigorous activity time

Quartile categories-hazard ratio $(95 \% \mathrm{Cl})$ relative to category 1

$\begin{array}{lllll}\text { (least time) } & 2 & 3 & 4 \text { (most time) } & P \text { value (trend }+\mathrm{t} \text { ) }\end{array}$

Categories defined from daily light intensity activity time‡

\begin{tabular}{|c|c|c|c|c|c|}
\hline Unadjusted & 1.00 & $0.55(0.37$ to 0.83$)$ & $0.45(0.29$ to 0.69$)$ & $0.50(0.33$ to 0.77$)$ & $<0.001$ \\
\hline $\begin{array}{l}\text { Socioeconomic§ and health } \uparrow \\
\text { factors }\end{array}$ & 1.00 & $0.59(0.38$ to 0.90$)$ & $0.50(0.32$ to 0.79$)$ & $0.53(0.34$ to 0.83$)$ & 0.003 \\
\hline 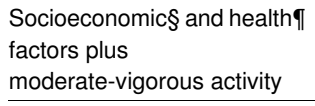 & 1.00 & $0.61(0.39$ to 0.93$)$ & $0.54(0.34$ to 0.86$)$ & $0.60(0.38$ to 0.96$)$ & 0.018 \\
\hline \multicolumn{6}{|c|}{ Categories defined from daily moderate-vigorous activity time ${ }^{\star *}$} \\
\hline Unadjusted & 1.00 & $0.54(0.36$ to 0.80$)$ & $0.50(0.33$ to 0.74$)$ & $0.28(0.17$ to 0.47$)$ & $<0.001$ \\
\hline $\begin{array}{l}\text { Socioeconomic§ and health } \uparrow \\
\text { factors }\end{array}$ & 1.00 & $0.63(0.41$ to 0.97$)$ & $0.58(0.36$ to 0.94$)$ & $0.36(0.20$ to 0.65$)$ & $<0.001$ \\
\hline $\begin{array}{l}\text { Socioeconomic§ and health } \mathbb{} \\
\text { factors plus light activity }\end{array}$ & 1.00 & $0.68(0.44$ to 1.05$)$ & 0.66 (0.40 to 1.08$)$ & $0.41(0.22$ to 0.76$)$ & 0.007 \\
\hline
\end{tabular}

*Based on change from baseline disability level to subsequent more severe level at two years in instrumental or basic activities of daily living (IADL/ADL) task limitation levels defined by none (no IADL/ADL limitations), mild (only IADL limitations), moderate (1-2 ADL limitations), severe ( $\geq 3$ ADL limitations).

†Linear trend test.

łLight activity quartile categories in minutes per day: Q1, <229 ( $n=466) ;$ Q2, 229-275 ( $n=447) ;$ Q3, 275-328 ( $n=453) ;$ Q4, $\geq 328(n=448)$.

§Age, sex, race/ethnicity, education, and income.

ףComorbidities (cancer, cerebrovascular disease, congestive heart failure, diabetes, gastrointestinal disease, pulmonary disease, kidney problems, myocardial infarction, rheumatic disease other than osteoarthritis, vascular disease), Center for Epidemiological Studies depression score, body mass index category, current smoking, knee osteoarthritis severity (Kellgren-Lawrence grade), knee pain (Western Ontario and McMaster University osteoarthritis score), knee symptoms, knee injury, other lower extremity joint pain, gait speed.

${ }^{\star *}$ Moderate-vigorous activity quartile categories in minutes per day: $Q 1,<4.3$ ( $\left.n=478\right) ;$ Q2, 4.3-12.1 ( $\left.n=455\right) ; Q 3,12.2-28.1$ ( $\left.n=450\right)$; Q4, $\geq 28.2$ ( $\left.n=431\right)$. 


\section{Figures}

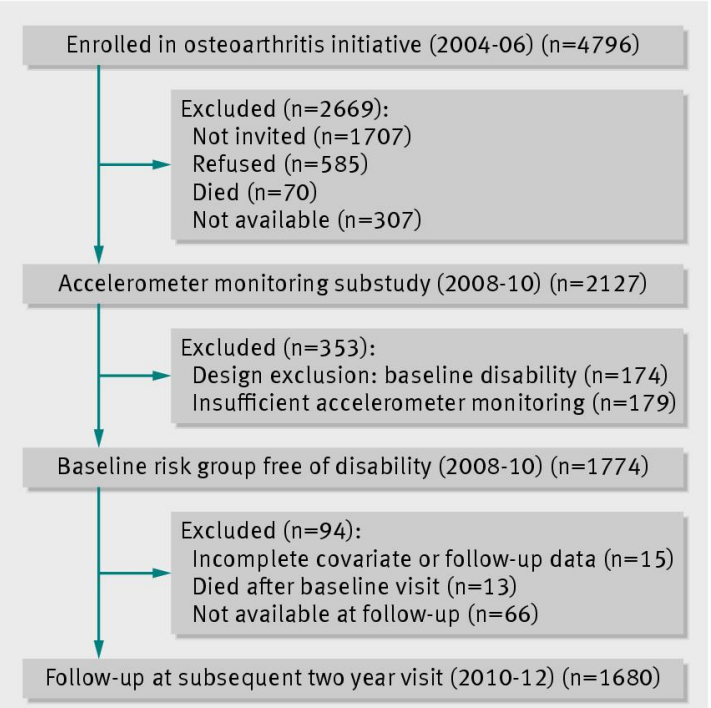

Fig 1 Flow of analytical sample of accelerometer participants at risk of disability onset through study follow-up

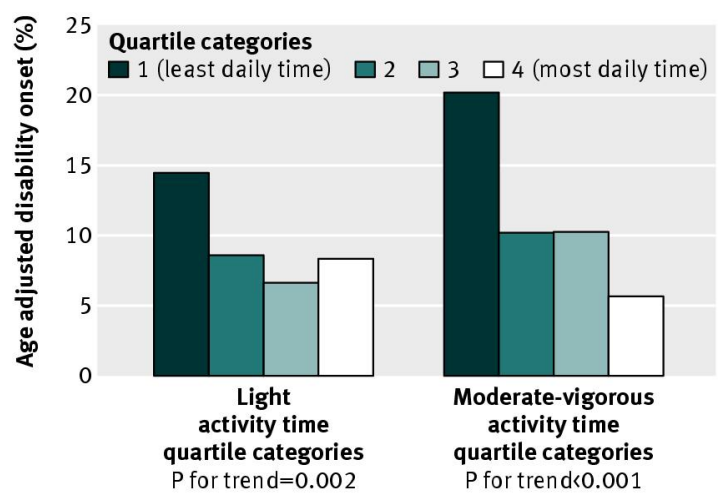

Fig 2 Age adjusted percentage of incident disability according to quartile categories of light physical activity and moderate-vigorous physical activity $(n=1680)$

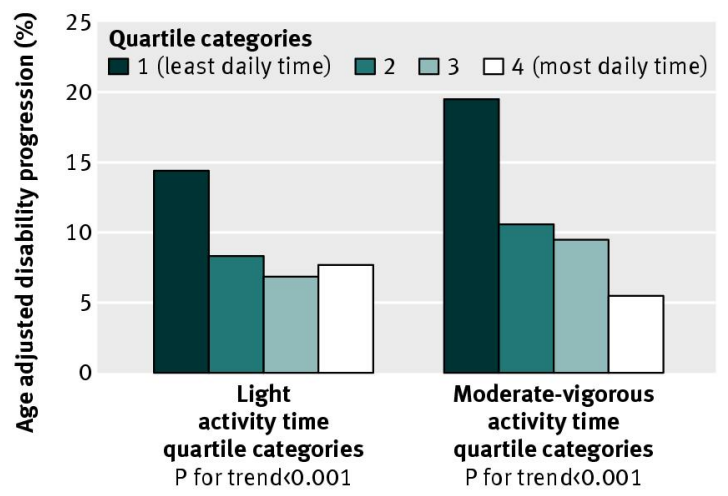

Fig 3 Age adjusted percentage of disability progression according to quartile categories of light physical activity and moderate-vigorous physical activity $(n=1814)$ 